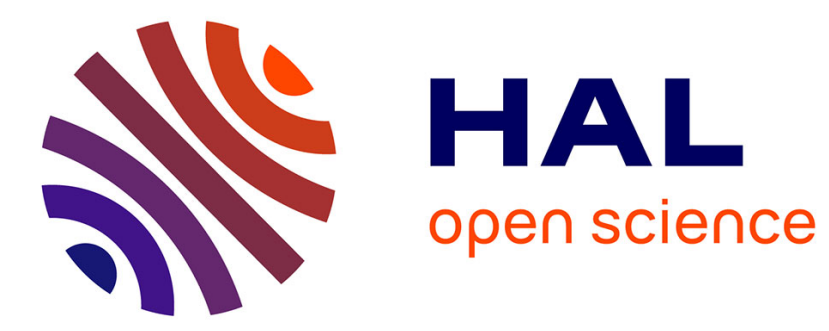

\title{
Evaluation of the tropospheric flows to a major Southern Hemisphere stratospheric warming event using NCEP/NCAR Reanalysis data with a PSU/NCAR nudging MM5V3 model
}

K. Wang

\section{To cite this version:}

K. Wang. Evaluation of the tropospheric flows to a major Southern Hemisphere stratospheric warming event using NCEP/NCAR Reanalysis data with a PSU/NCAR nudging MM5V3 model. Atmospheric Chemistry and Physics Discussions, 2008, 8 (2), pp.7953-7976. hal-00304127

\section{HAL Id: hal-00304127 \\ https://hal.science/hal-00304127}

Submitted on 22 Apr 2008

HAL is a multi-disciplinary open access archive for the deposit and dissemination of scientific research documents, whether they are published or not. The documents may come from teaching and research institutions in France or abroad, or from public or private research centers.
L'archive ouverte pluridisciplinaire HAL, est destinée au dépôt et à la diffusion de documents scientifiques de niveau recherche, publiés ou non, émanant des établissements d'enseignement et de recherche français ou étrangers, des laboratoires publics ou privés. 


\section{Evaluation of the tropospheric flows to a} major Southern Hemisphere stratospheric warming event using NCEP/NCAR Reanalysis data with a PSU/NCAR

\section{nudging MM5V3 model}

\section{K. Wang}

Department of Atmospheric Sciences, National Central University, Chung-Li, Taiwan

Received: 12 February 2008 - Accepted: 26 March 2008 - Published: 22 April 2008

Correspondence to: K.-Y. Wang (kuoying @ mail.atm.ncu.edu.tw)

Published by Copernicus Publications on behalf of the European Geosciences Union.

MM5V3 modeling of the 2002 SH stratosphere

K. Wang

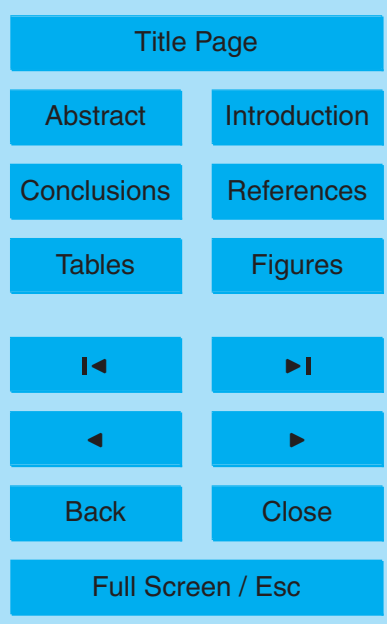

Printer-friendly Version

Interactive Discussion

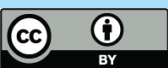




\section{Abstract}

Previous studies of the exceptional 2002 Southern Hemisphere (SH) stratospheric warming event lead to some uncertainty, namely the question of whether excessive heat fluxes in the upper troposphere and lower stratosphere are a symptom or cause

5 of the $2002 \mathrm{SH}$ warming event. In this work, we use a hemispheric version of the MM5 model with nudging capability and we devised a novel approach to separately test the significance of the stratosphere and troposphere for this year. We paired the flow conditions from 2002 in the stratosphere and troposphere, respectively, against the conditions in 1998 (a year with displaced polar vortex) and in 1948 (a year with strong polar vortex that coincided with the geographical South Pole). Our experiments show that the flow conditions from below determine the stratospheric flow features over the polar region. Regardless of the initial stratospheric conditions in 1998 or 1948, when we simulated these past stratospheres with the troposphere/lower stratosphere conditions constrained to 2002 levels, the simulated middle stratospheres resemble those observed in 2002 stratosphere over the polar region. On the other hand, when the 2002 stratosphere was integrated with the troposphere/lower stratosphere conductions constrained to 1948 and 1998, respectively, the simulated middle stratospheric conditions over the polar region shift toward those of 1948 and 1998. Thus, our experiments further support the wave-forcing theory as the cause of the $2002 \mathrm{SH}$ warming event.

\section{Introduction}

Prior to September 2002, occasional general circulation model experiments were considered to have defects in the models when they showed warming in the SH stratosphere (Baldwin et al., 2003; Scaife et al., 2005). As such, the unprecedented warming of the 2002 Antarctic winter stratosphere was a truly extraordinary event (WMO, 2002; Varotsos, 2003, and the references therein; Baldwin et al., 2003). Since no major warming hd been observed before in the $\mathrm{SH}$ since regular observations of the region

MM5V3 modeling of the 2002 SH stratosphere

K. Wang

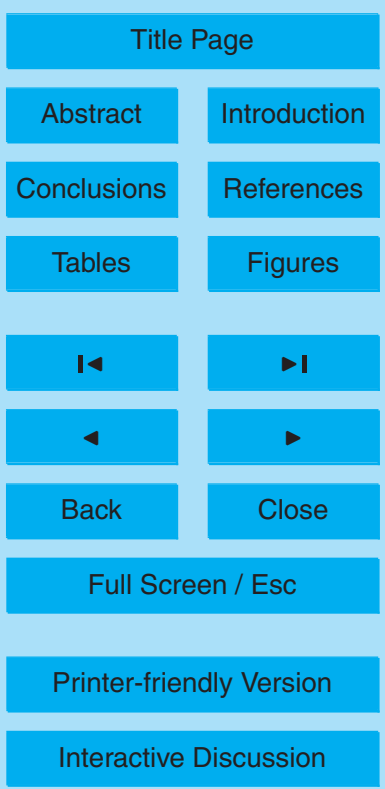


began in 1957 (Andrews et al., 1987; Shepherd et al., 2005), this dramatic event provided an excellent opportunity to explore the mechanism linking the troposphere and stratosphere.

It has been argued that the $2002 \mathrm{SH}$ warming event was rooted in the troposphere.

5 For example, from an analysis of a global model forecasts of the $2002 \mathrm{SH}$ warming, Allen et al. (2006) argued that large amounts of upward energy propagation from $500 \mathrm{hPa}$, at a region of strong blocking over the South Atlantic, caused extremely large heat fluxes at $100 \mathrm{hPa}$ that in turn led to the SH warming; Nishii and Nakamura (2004) argued that blocking over the South Atlantic troposphere caused the $2002 \mathrm{SH}$ event;

10 Scaife et al. (2005) countered that the 2002 SH warming event could be explained as a response to more vigorous planetary waves near the tropopause; Manney et al. 2005) showed that strong forcing at $100-\mathrm{hPa}$ could be viewed as the primary cause of the warming, and that the stratospheric flow was largely determined by the $100 \mathrm{hPa}$ geopotential heights; Kushner and Polvani (2005) demonstrated that a very simple model of the $\mathrm{SH}$ stratosphere, forced only by tropospheric baroclinic eddies, could produce $\mathrm{SH}$ stratospheric warming characteristically similar to the observed 2002 event. It has been shown that numerical weather prediction models were able to predict the 2002 SH warming events in advance (Simmons et al., 2005; Allen et al., 2006); that idealized model experiments qualitatively reproduced the $\mathrm{SH}$ stratospheric warming results when the tropospheric baroclinic wave forcing eddies were present (Kushner and Polvani, 2005); and that the $2002 \mathrm{SH}$ vortex splitting could be reproduced through the resonant growth of the planetary waves in the stratosphere to the forcing frequency of the troposphere (Esler et al., 2006).

Most of these studies used the excessive heat flux diagnosed in the upper tropo25 sphere, which had pressures measuring $100 \mathrm{hPa}$ to $200 \mathrm{hPa}$, as evidence that strong tropospheric wave forcing caused this event (e.g., Newman and Nash, 2005). But Charlton et al. (2005) countered that the exceptional heat flux may be a symptom of the exceptional stratospheric warming rather than the cause. Charlton et al. (2005) concluded that because the variance in geopotential height at $60^{\circ} \mathrm{S}$ occurred in the

\section{MM5V3 modeling of the 2002 SH stratosphere \\ K. Wang}

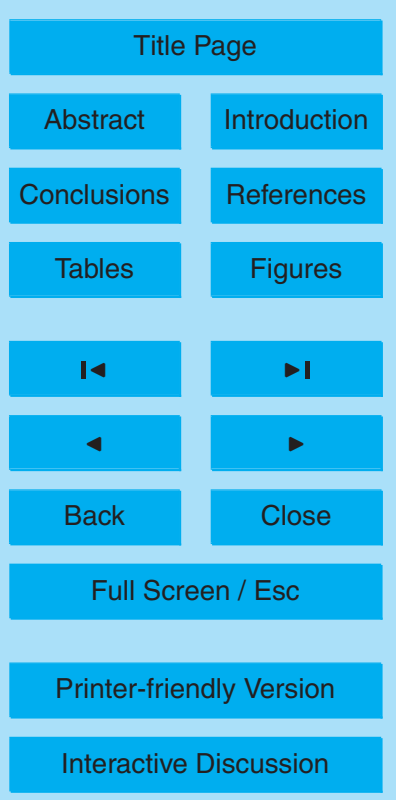


troposphere and stratosphere simultaneously in the spring of 2002, the forcing did not necessarily come from below. Using a general circulation model, with a lower boundary at $10 \mathrm{hPa}(\sim 30 \mathrm{~km})$ and an upper boundary of $500 \mathrm{~km}$ and forced by the 2002 National Center for Environmental Prediction (NCEP) reanalysis, Liu and Roble (2005)

5 argued that the $2002 \mathrm{SH}$ warming event was caused by a downward propagation of wind and temperatures changes that occurred in the mesosphere. Notably, Liu and Roble (2005)'s experiments were forced by the 2002 NCEP reanalysis at the $30 \mathrm{~km}$ lower boundary. It is unclear whether downward propagation of wave disturbance from the mesosphere to the stratosphere could result if not forced by the 2002 reanalysis at $1030 \mathrm{~km}$.

With all this in mind, we must still ask: were tropospheric flows critical to the occurrence of the dramatic $2002 \mathrm{SH}$ stratospheric warming? To answer this question, we developed a novel approach to test the importance of the 2002 stratospheric and tropospheric flows, respectively. Since previous works analyzed the tropospheric and stratospheric flow conductions as an integrated flow system, it was difficult to distinguish the cause and effect issue raised by Charlton et al. (2005). In this work we attempt a different approach. We actually break down the the tropospheric master/stratospheric slave model, as guided by Charlton et al. (2005), and test each flow regime separately. Here, we shall determine whether the exceptional $2002 \mathrm{SH}$ stratospheric warming event could be duplicated in experiments if the stratospheric flows from other years were subjected to the same forcing of the 2002 troposphere. On the other hand, we ask if $2002 \mathrm{SH}$ warming event could occur if the 2002 stratospheric flows were subjected to the tropospheric conditions from other years?

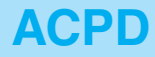

8, 7953-7976, 2008

\section{MM5V3 modeling of} the 2002 SH stratosphere

K. Wang

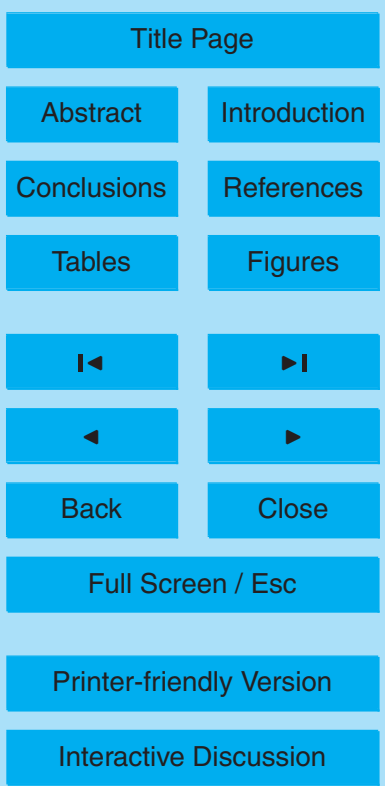




\section{Data and models}

\subsection{NCEP/NCAR reanalysis data}

This work relies on the three-dimensional NCEP/ National Center for Atmospheric Research (NCAR) Reanalysis data obtained from the Climate Diagnostic Center 5 (CDC)/National Oceanic and Atmospheric Administration (NOAA) (Kalnay et al., 1996; Kistler et al., 2000). NCEP/NCAR Reanalysis is one of the most widely used atmospheric dataset (e.g., Kalnay and Cai, 2003). Two important characteristics distinguish NCEP/NCAR Reanalysis dataset from other datasets: its longterm coverage (1948present), and its open accessibility. In the absence of these two factors, this research 10 would not have been possible. We used NCEP/NCAR Reanalysis data as (i) initial conditions and boundary conditions for the MM5V3 simulations; and (ii) gridded analysis data for the four dimensional data nudging simulations.

\subsection{A hemispheric PSU/NCAR MM5V3 model}

The fifth-generation Pennsylvania State University/National Center for Atmospheric Research Mesoscale Model (PSU/NCAR MM5) is a research tool supported by NCAR for community numerical weather prediction and mesoscale modeling research (e.g., Dudhia and Bresch, 2002, and the references therein). The PSU/NCAR MM5 is a proven, state-of-the-art creation and has had numerous applications since its initial inception by Anthes and Warner (1978).

In order to understand the process that produced this extraordinary 2002 Antarctic vortex split, we will perform a series of direct simulations of the stratospheric flow of September 2002. Figure 1 shows the horizontal domain used in the three-dimensional modeling experiments. Dudhia and Brech (2002) developed a global version of the PSU/NCAR Mesoscale Model that combines two polar stereographic projections, one of the Northern Hemisphere and one of the Southern Hemisphere, to form a global version of the model. In this work, we use only the Southern Hemisphere domain. The

MM5V3 modeling of the 2002 SH stratosphere

K. Wang

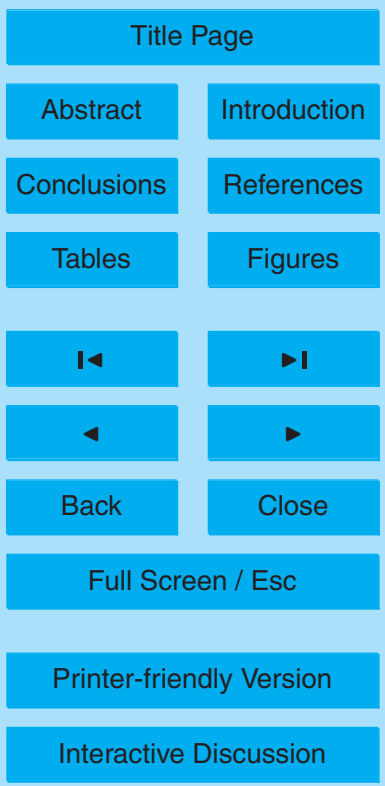


boundary conditions from the NCEP/NCAR Reanalysis dataset are used as boundary conditions for the regions outside the model domain.

For the purpose of this work, the distributed-memory version of the PSU/NCAR MM5V3 model is used (Wang et al., 2005). We apply the MM5V3 modeling system

5 to direct simulations of the September 2002 stratosphere. We also apply the MM5V3 modeling system's four-dimensional data nudging capability, and we conduct several nudging simulations to investigate the importance of tropospheric forcing. In this work, the model has 31 vertical levels, and a $140 \mathrm{~km}$ by $140 \mathrm{~km}$ horizontal resolution. The $\sigma$ values for the model levels are: $0,0.005,0.015,0.025,0.035,0.045,0.055,0.065$, $10 \quad 0.08,0.1,0.15,0.2,0.25,0.30,0.35,0.4,0.45,0.50,0.55,0.6,0.65,0.7,0.75,0.8$, $0.85,0.89,0.93,0.96,0.98,0.99$, and 1 . The vertical $\sigma$ coordinate is defined as $\sigma=\left(p-p_{t}\right) /\left(p_{s}-p_{t}\right)$. Here $p_{t}$ is the model's top pressure, which is a constant $10 \mathrm{hPa}$; $p_{s}$ is the terrain surface pressure, and $p$ is the pressure at $\sigma$. The use of the $10 \mathrm{hPa}$ model top is an optimal choice under the current MM5V3 configuration, and has been

15 used in several previous studies of the stratospheric flows. Allen (2003) used MM5 with a model top at $10 \mathrm{hPa}$ to study stratospheric turbulence. Allen et al. (2006) examined two 5-day forecasts of geopotential heights at $10 \mathrm{hPa}$ during the $2002 \mathrm{SH}$ warming event using an operational model with model top at $1 \mathrm{hPa}$ and $0.005 \mathrm{hPa}$, respectively. They found that the distinctive warming high and the vortex with lobes from these two forecast simulations closely resembled each other. Simmons et al. (2005) found that the forecasts using the 40 -level model with a model top at $10 \mathrm{hPa}$ were reasonably skillful but less accurate than the results using the 60 -level model with to top at $0.1 \mathrm{hPa}$ $(\sim 65 \mathrm{~km})$.

It would be ideal to set a model top higher than the $10 \mathrm{hPa}$, because the upper 25 boundary of the model reflects vertically propagating wave activity. Boville and Chen (1988) showed, using the climate of a 15-level general circulation model with a model top at $10 \mathrm{hPa}(\sim 30 \mathrm{~km})$ cimpared with a 26-level model with a model top at $0.1 \mathrm{hPa}$, that an upper boundary of $10 \mathrm{hPa}$ showed the effects of stronger polar night jets and colder polar temperatures in the lower stratosphere. This result was due to more wave

MM5V3 modeling of the 2002 SH stratosphere

K. Wang

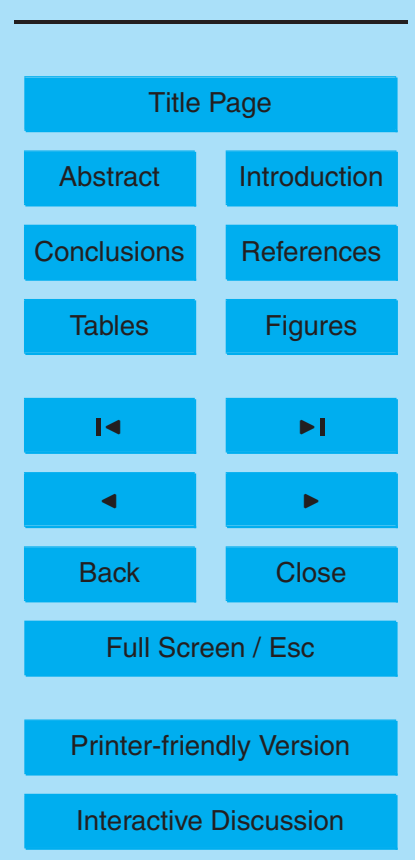


reflection, which leads to increasing wave amplitude, which leads to changing heat and momentum fluxes, which leads to an increase in the net westerly forcing to the zonal mean wind, which results in a much stronger polar night jet and the very cold lower stratosphere temperatures mentioned above. Another advantage of a higher model top 5 boundary is that the effects of the upper stratosphere and the mesosphere can be considered, e.g. downward propagation of winds and temperatures from the mesosphere shown in Liu and Roble (2005). However, other uncertainties, such as the representation of the upper boundary and the lack of explicit representation of the effects of breaking gravity waves, require further development of the MM5V3 model if the model 10 top is set at altitudes higher than $10 \mathrm{hPa}$. We have experimented with several MM5V3 models using model top above $10 \mathrm{hPa}$, but the instability, most likely resulting from the model being unable to control the strength of the polar vortex, prevented us from using a model top above $10 \mathrm{hPa}$. On the other hand, several previous works have shown that $10 \mathrm{hPa}$ top models were capable of reproducing stratospheric warming events occurred before (e.g., see Andrews et al., 1987, and reference therein; Simmons et al., 2005), indicating that the key mechanisms responsible for the stratospheric warming processes are largely self-contained in the flow regions below $10 \mathrm{hPa}$. Hence, we use the $10 \mathrm{hPa}$ model top configuration not for its absolute accuracy but for its accurate simulation of dynamical processes compared to those delivered using a higher model top (e.g., Simmons et al., 2005).

Table 1 shows a list of the twelve MM5V3 experiments. Each experiment was initialized at 12:00 UTC on 12 September. In the control run, there is no nudging of the analysis data. Experiments 1 through 7 show a series of nudging experiments, in which different vertical extents of the 2002 tropospheric flows were used as constraints of the analysis data, while the model stratospheric flows were left to evolve during each 288$\mathrm{h}$ simulation. These experiments were designed to determine the minimum vertical extent (if a minimum existed) that would be required to reproduce the warming event. From these experiments, we found that if the atmospheric flows below $50 \mathrm{hPa}(\sim 21 \mathrm{~km})$ were constrained to the analysis data, then the model produced the $2002 \mathrm{SH}$ warming

\section{MM5V3 modeling of the $2002 \mathrm{SH}$ stratosphere \\ K. Wang}

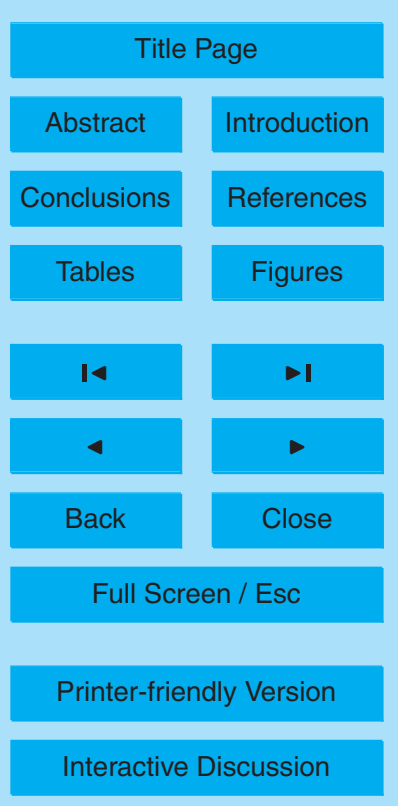


and the vortex splitting similar to actual observations. Thus we identified the $50 \mathrm{hPa}$ pressure level as the upper boundary for the influence of flows from below.

Experiments 8 and 9, used 1948 and 1998 simulations, respectively, and each model was run for $312 \mathrm{~h}$ with the flows below $50 \mathrm{hPa}$ constrained to the 2002 conditions while 5 the flows above $50 \mathrm{hPa}$ were left to evolve. These experiments were designed to test the robustness of the 2002 flows, from the surface up to $50 \mathrm{hPa}$. In experiments 10 and 11 , the model was run for two sets of the 312-h simulations. Experiment 10 was run with the flow conditions below $50 \mathrm{hPa}$ constrained to the 1948 conditions, and Experiment 11 was run with flow conditions below $50 \mathrm{hPa}$ constrained to the 1998 conditions.

10 These experiments were designed to test if the 2002 stratosphere could still produce the $2002 \mathrm{SH}$ warming event when flow conditions below $50 \mathrm{hPa}$ from other years were used. These years were carefully selected. In 1998, the center of the Antarctic polar vortex was significantly displaced from the geographical South Pole. In contrary, the Antarctic polar vortex in 1948 showed a strongly symmetrical flow structure with the 15 vortex center directly over the Pole.

\section{Results}

\subsection{Direct simulations without nudging}

Figure $2 \mathrm{a}$ shows the $30-\mathrm{hPa}$ temperature and wind analysis at 12:00 UTC on 24 September 2002. The split of the polar vortex and the warming of the Antarctic stratosphere (with a maximum temperature of $243.7 \mathrm{~K}$ ) are clearly present. The warming area is accompanied by a well-defined anticyclonic circulation, along with two split vortices with low temperatures $\left(196.2 \mathrm{~K}\right.$ in the vortex located at about $10^{\circ} \mathrm{E}-20^{\circ} \mathrm{E}$, and $198.4 \mathrm{~K}$ in the vortex located at about $110^{\circ} \mathrm{W}$ ) and their associated cyclonic circulations. These features satisfy the synoptic definition of a major stratospheric $\mathrm{SH}$ warming event (Andrews et al., 1987).

Figure $2 \mathrm{~b}$ shows a 72-h simulation of temperature and wind at 12:00 UTC on 24

\section{MM5V3 modeling of the 2002 SH stratosphere \\ K. Wang}

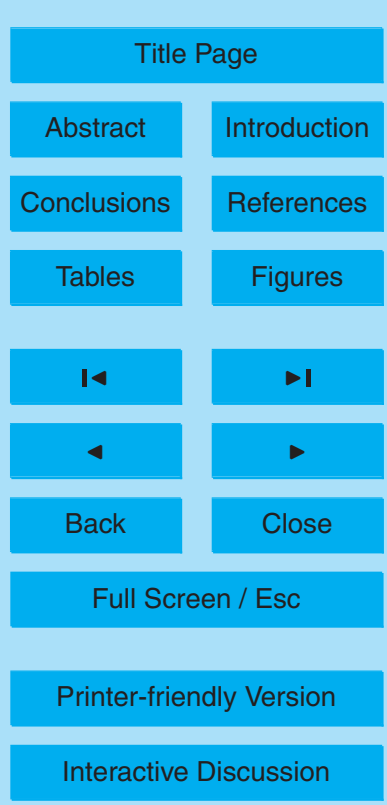


September 2002. The model was initialized at 12:00 UTC 21 September 2002. The main features, including major stratospheric warming with the anticyclonic circulation, a split polar vortex, and associated cyclonic circulations, are reproduced by the model. However, the model predicts a stronger vortex at $20^{\circ} \mathrm{E}$ with a lowest temperature of $5194.5 \mathrm{~K}$, a weaker vortex at $110^{\circ} \mathrm{W}$ with a minimum temperature of $204.5 \mathrm{~K}$, and less warming (a maximum temperature of $241.7 \mathrm{~K}$ ) in the anticyclonic region than were actually observed. This 72-h simulation shows that the model configuration we used in this work is able to reproduce the main features of the $2002 \mathrm{SH}$ warming event.

Figure 3 a shows a 288-h simulation of temperature and wind at 12:00 UTC on 24

10 September 2002. The model produces a polar vortex displaced from the geographical South Pole, with a lowest in-vortex temperature of $195 \mathrm{~K}$, and less extensive warming over the Antarctic region. This 288-h forecast resembles previous Antarctic stratosphere vorticies such as the one in 1998 (see discussion in the next section). This characteristically displaced vortex, unlike a splitting vortex from a longer (10-day) forecast, has been found in other simulations (e.g., Figs. 4 and 5 of Simmons et al., 2005; Fig. 2 of Allen et al., 2006). Allen et al. (2006) supposed that model limitations for forecasting tropospheric blocking are the likely cause of less accurate longer forecasts. Based on the NCEP reanalysis, Niishi and Nakamura (2004) argued that the blocking over the South Atlantic, forced by anomalous deep convection in the South Pacific Convergence Zone, was the source of the wavetrains that led to the $2002 \mathrm{SH}$ warming.

\subsection{Nudging simulations}

In order to quantify the influence of tropospheric forcing to the development of the 2002 Antarctic SH warming event, we performed a series of model experiments to identify the region where the tropospheric forcing was significant to the warming event.

25 The most important factor in these experiments was the introduction of the observed (analyzed) tropospheric conditions into the model troposphere as the model integrates forward in time. Here we employed the nudging method developed in the PSU/NCAR MM5 modeling system (Grell et al., 1994) for these tropospheric forcing experiments.

\section{MM5V3 modeling of the 2002 SH stratosphere \\ K. Wang}

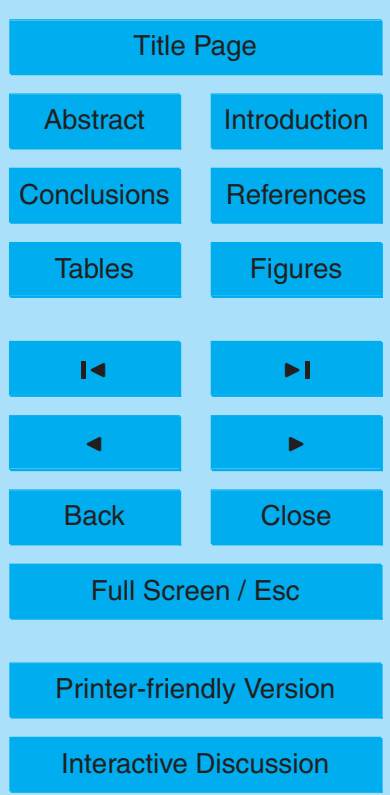


Notice that in the following discussions, the model has been integrated forward $288 \mathrm{~h}$, so the results discussed in this section contain the same simulation length $(288 \mathrm{~h})$ as Fig. 3a.

Figure $3 \mathrm{~b}$ shows the $30-\mathrm{hPa}$ temperature and wind fields from a 288-h simulation run 5 with nudging in the region below $325 \mathrm{hPa}$ (an altitude of about $9 \mathrm{~km}$ ). The simulation was verified at 12:00 UTC on 24 September 2002. A comparison of Fig. 3b with Fig. 3a, clearly demonstrates the effect of tropospheric forcing on stratosphere flow. The characteristic warming of the polar region is reproduced by the model. Most importantly, the overlapping pattern of extensive anticyclonic flow with the major high temperature 10 region can be clearly seen, indicating that the model replicated a major SH warming. There are discrepancies between the nudging simulation and analysis. The highest temperature in the anticyclone $(233 \mathrm{~K})$ was lower than in the analysis $(243 \mathrm{~K})$, and the lowest temperature in the cyclone (189 K) was lower than the analysis (196 K).

While Fig. 3b shows a displaced polar vortex at the geographical South Pole, the real 15 situation was a split polar vortex. Hence, we systematically raised the upper boundaries of the nudging region, providing the model with more analysis data to see if the model was capable of producing a splitting polar vortex. Figure $3 \mathrm{c}$ shows a simulation in which upper boundary of the tropospheric nudging region has been raised to about $225 \mathrm{hPa}$ (about $11 \mathrm{~km}$ height). Here we observe that, in addition to the common features shown in Fig. 3c, an area of low temperatures gradually appears over the $120^{\circ} \mathrm{W}-80^{\circ} \mathrm{W}$ region. This is the simulation's first sign of an emerging splitting vortex. As the upper boundary of the tropospheric nudging region was raised further, to $125 \mathrm{hPa}$ (about $15 \mathrm{~km}$ ), Fig. 3d, we see noticeable developments: the lowest temperature inside the polar vortex has increased to $193 \mathrm{~K}$, warm temperatures show a tendency to extend out from the pole, and an area of low temperatures steadily grows over the $120^{\circ} \mathrm{W}-80^{\circ} \mathrm{W}$ region. When the upper boundary of the nudging region was raised to about $72 \mathrm{hPa}$ (about $19 \mathrm{~km}$ height), the second vortex at $90^{\circ} \mathrm{W}$ is noticeable, Fig. 4 a.

This second vortex becomes more prominent if the upper boundary of the nudging

\section{MM5V3 modeling of the 2002 SH stratosphere \\ K. Wang}

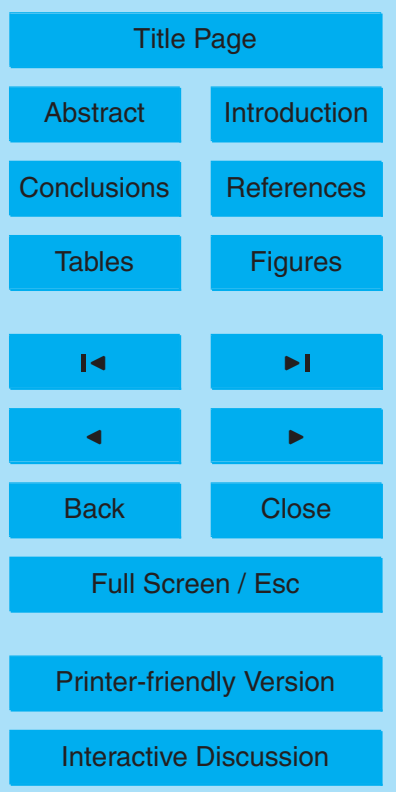


is raised to near $50 \mathrm{hPa}$ (about $21 \mathrm{~km}$ height), Fig. 4b. In this simulation the two lobes of the splitting polar vortex are separated by the advancing warm air. As we move the upper boundary of the nudging region even higher to $30 \mathrm{hPa}$ (about $24 \mathrm{~km}$ ), Fig. 4c, the results are completely constrained to the analysis. Fig. $4 \mathrm{~d}$ shows results when 5 the model domain is entirely integrated with the analysis, and produces the expected nudging simulation identical to that of the analysis.

These simulations show that as the upper boundary of the nudging region is gradually raised from $9 \mathrm{~km}$ to $21 \mathrm{~km}$, the warming area over the South Antarctic stratosphere grows, the first emerging vortex becomes smaller, and the second emerging vortex 10 gradually emerges. The second emerging vortex becomes identifiable in our simulations when the nudging information from the lower stratosphere is used to constrain the simulation.

Here we demonstrate that the hypothesis of tropospheric forcing, as first formulated by Matsuno (1971), is useful in explaining the warming of the stratosphere by an ex15 ternal forcing mechanism from the troposphere. From a 100-yr integration of a simple global circulation model, Taguchi and Yoden (2002) found that stratospheric flows showed little interannual variation in any seasons when the simulation was run without topography, and dynamically active stratospheric flows with large interannual variations in any season run with topography included. The use of accurate tropospheric conditions can dramatically improve stratospheric forecasts as shown when comparing Fig. 3a with Fig. 3b, a conclusion also reached by Allen et al. (2006). However, in order to reproduce the splitting vortex, more information is needed from the lower stratosphere. As more and more layers are added in the lower stratosphere, the simulated flows bear closer resemblance to those observed. Apparently, the troposphere initiates the large scale disturbances in the stratosphere. However, to have an exceptional SH warming event with a splitting polar vortex, the stratospheric flows in the lower stratosphere must also be unique. Perhaps this combination - when the right tropospheric forcing meets the right lower stratospheric flows - is simply so unusual that major SH warming has not been observed before. Perhaps the weak tropospheric forcing in the

\section{MM5V3 modeling of the 2002 SH stratosphere \\ K. Wang}

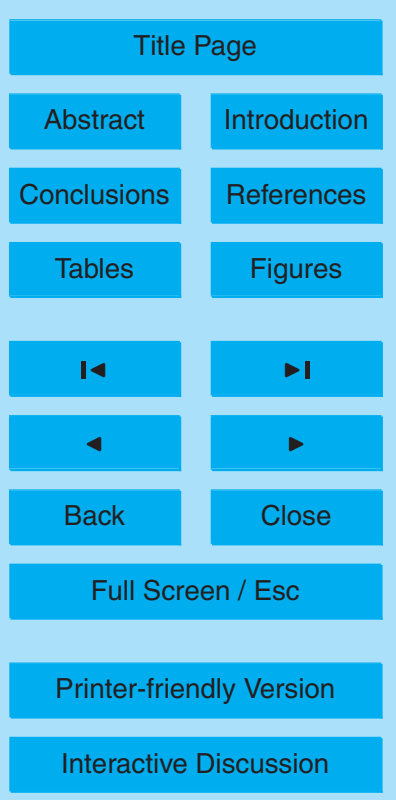


Southern Hemisphere must wait for the right lower stratospheric conditions to magnify and/or resonate its effect (Andrews et al., 1987; Esler et al., 2006).

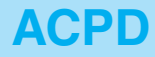

\subsection{Test of the 2002 troposphere}

In order to further investigate the importance and significance of the tropospheric and 5 lower stratospheric conditions in 2002 , we performed two completely different set of experiments (Experiments 8 and 9 of Table 1) using the nudging method with different combinations of stratospheric and tropospheric flow conditions. Our first set of experiments tested what impact the 2002 tropospheric conditions would have if we put stratospheres from other years under the influence of the 2002 troposphere?

Figure $5 \mathrm{~b}$ shows the $30-\mathrm{hPa}$ temperature and wind fields from a 312-h simulation of the 2002 stratosphere, with the tropospheric nudging using data from 2002. The model was verified against the analysis at 12:00 UTC on 25 September 2002, Fig. 5a. When the 1948 stratospheric conditions were modeled with the 2002 tropospheric conditions, Fig. $5 \mathrm{c}$ shows a 312-h simulation of the $30-\mathrm{hPa}$ temperature and wind fields verified at 15 12:00 UTC on 25 September 1948. The result clearly shows that the original strong polar vortex of 1948 (Fig. 6c) has been replaced by the warming temperatures over the polar region. The polar vortex is no longer a recognizable shape when viewed with the temperature contours, and the spatial distribution of the high temperature region is characteristically similar to the $2002 \mathrm{SH}$ warming region.

20 We subjected the 1998 stratosphere to the 2002 tropospheric conditions, and the results are shown in Fig. 5d. As in Fig. 5c, we observed the warming of the polar region, the advancing of high temperatures across the pole, and discernible anticyclonic flow patterns over the high temperature region. Figure $6 \mathrm{~d}$ shows the $30 \mathrm{hPa}$ temperature and wind analysis at 12:00 UTC 25 September 1998, indicating a significant high tem-
8, 7953-7976, 2008

\section{MM5V3 modeling of} the 2002 SH stratosphere

K. Wang

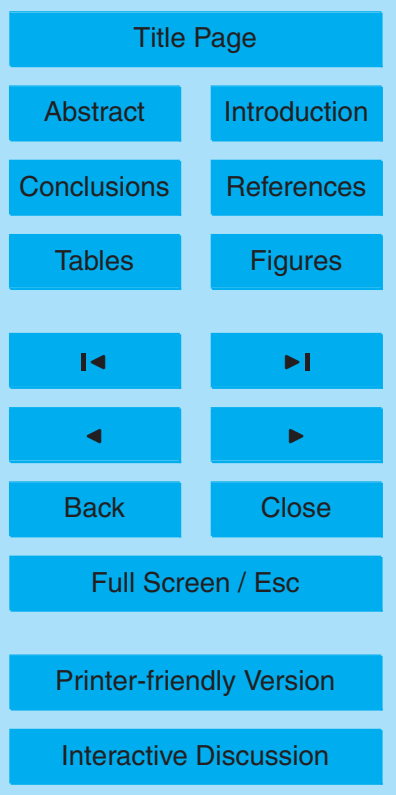
temperature area pushes the polar vortex off the geographical South Pole, the polar vortex maintains its well-defined temperature and cyclonic wind structures and shows no occurrence of a splitting polar vortex. Actually, this situation more closely resembles 
the one we see in Fig. 3b, where only the tropospheric domain of data (below $9 \mathrm{~km}$ ) is used in the nudging simulation. Thus it is likely that the 1998 Antarctic stratosphere was also subjected to strong forcing from the troposphere.

These simulations show that the warming in the anticyclonic area is a combined 5 effect of tropospheric forcing and lower stratospheric flow, but the formation of a splitting vortex and their associated cyclonic flows requires the contributions from higher up altitudes (e.g., Charton et al., 2005; Liu and Roble, 2006). There are areas with welldefined high temperatures as seen in Figs. $5 \mathrm{c}$ and $\mathrm{d}$, which are characteristically similar to those observed in 2002. However, none of the above experiments is capable 10 of producing well-defined anticyclonic flow patterns over the high temperature region, along with a splitting polar vortex. Therefore the middle to upper stratosphere should play an important role in the forming of the splitting vortex.

\subsection{Test of the 2002 stratosphere}

Our second set of experiments (Experiments 10 and 11 of Table 1) test the strength 15 of the 2002 stratospheric conditions against tropospheric conditions from other years. Figure $6 \mathrm{a}$ shows the $30 \mathrm{hPa}$ temperature and wind fields from a 312-h simulation using the 2002 stratosphere with the tropospheric nudging using data from 1948. The model is verified against the analysis at 12:00 UTC on 25 September 2002, Fig. 5a. The resulting simulated 2002 stratosphere shows no similarities to the analysis. For example, the polar vortex remains firmly over the polar region, showing no sign of distortion, elongation, or being pushed off the geographical South Pole. In fact, the polar stratosphere in this simulation looks more like the one that occurred in 1948, Fig. 6c.

Figure $6 \mathrm{~b}$ shows another simulation with the tropospheric nudging using data from 1998. This simulation shows a more disturbed polar vortex; a significantly larger warm25 ing region; and a displaced polar vortex resembling the displaced vortex that occurred in 1998, Fig. 5 d. Hence, these experiments demonstrate that the stratospheric flow in 2002 can be nudged toward the 1948/1998 conditions if the 1948/1998 tropospheric flows are used.

\section{MM5V3 modeling of the 2002 SH stratosphere \\ K. Wang}

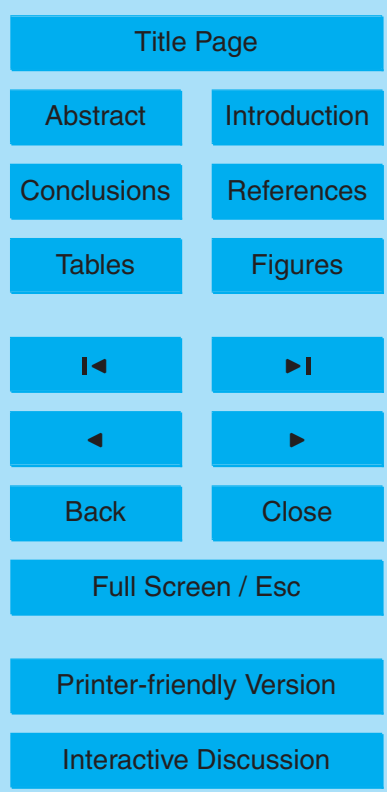


The above experiments also reveal more wave activity over latitudes outside polar region occurred in the warming experiments than in the non-warming experiments. For example, compare the 1948 stratosphere, Fig. 6c, in which no major warming was found over the polar region, with Fig. $5 \mathrm{c}$, in which a major warming was produced us5 ing the 2002 troposphere, the warming experiment shows more wave activity than in the non-warming experiment. Similarly, more wave activity appears outside the polar latitudes appear in the 1998 warming experiment, Fig. 5d, than in the non-warming experiment, Fig. 6 d. As for 2002 , we found more wave activity outside polar latitudes in the warming experiment, Fig. 5b, than in the non-warming experiment, Fig. 6a. This 10 phenomenon in our experiment is consistent with previous findings, i.e., a more resonating stratosphere with respect to a more rigorous forcing from the troposphere.

\section{Discussion and summary}

Though Charlton et al. (2005) questioned the validity of the tropospheric master/stratospheric slave model as an explanation of the $2002 \mathrm{SH}$ warming event, and 15 despite Liu and Robel (2006), who showed preconditioning and downward propagation of winds and temperatures from the mesosphere to the stratosphere in their 30$500 \mathrm{~km}$ stratosphere-mesosphere-ionosphere simulation, our experiments support a picture which is consistent with previous findings, namely, that forcing from surface, through the troposphere, to the lower stratosphere was the main cause of the 2002 $20 \mathrm{SH}$ warming event. Using the powerful modeling and nudging capabilities of the MM5 model, we have run several experiments to test on the factors that might have led to the 2002 SH warming event. We also designed two specific sets of experiments to test the robustness of the 2002 troposphere and stratosphere against the tropospherestratosphere flow conditions of 1948 and 1998, respectively.

25 We found that the flow conditions from below determine the stratospheric flow features over the polar region. Regardless of the initial conditions from either 1998 or 1948 , when these conditions were simulated with the troposphere/lower stratosphere

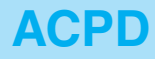

8, 7953-7976, 2008

\section{MM5V3 modeling of} the 2002 SH stratosphere

K. Wang

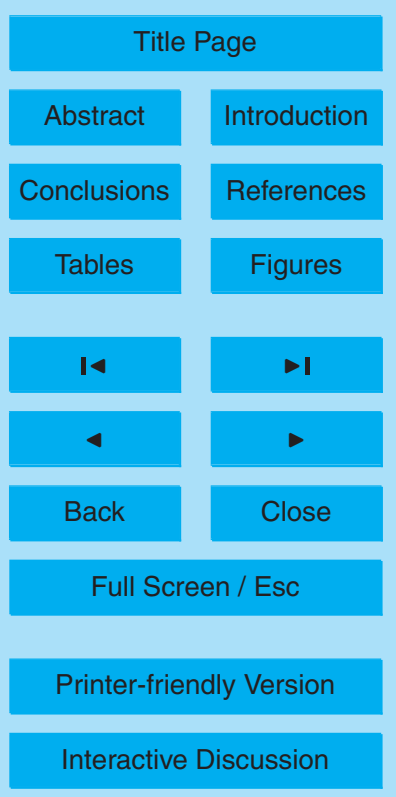


conditions from 2002, middle stratospheric flows also resembled those observed in 2002 over the polar region. On the other hand, when the 2002 stratosphere was integrated with the troposphere/lower stratosphere conditions from 1948 and 1998, respectively, the resulting middle stratospheric conditions over the polar region veered 5 toward those of 1948 and 1998. When comparing middle stratosphere from the warming experiment with non-warming experiment, more wave activity was found outside the polar region in the warming experiment than in the non-warming experiment. These experiments confirm the wave-forcing theory to explain the $2002 \mathrm{SH}$ warming event (e.g., Andrews et al., 1987).

10 Though we have demonstrated the uniqueness of the 2002 troposphere/lower stratosphere compared to conditions in 1998 and 1948, it is still unclear exactly what triggered the $2002 \mathrm{SH}$ warming event from below. Some have pointed to blocking in the troposphere over the Southern Atlantic as the root cause (Nishii and Nakamura, 2004; Allen et al., 2006), but it is unclear exactly how this blocking was unique enough to trig15 ger the great $2002 \mathrm{SH}$ warming event. Given the fact that blocking occurs frequently in the SH (e.g., Trenberth and Mo, 1985; Damiao et al., 2006), more modeling tests are needed before we can confidently state the exact source of the $2002 \mathrm{SH}$ warming event. We suggested that the proposed mechanism should be tested not only with the 2002 flow conditions but also with flows from other years. The MM5 nudging technique developed in this work will be useful for conducting these experiments.

Acknowledgements. The author is very grateful to P. Hadjinicolaou (Frederick Institute of Technology, Cyprus) for his review and comments on the manuscript. We are very grateful to UCAR/NCAR for the original MM5V3 model, NCEP for the reanalysis data (1948-present), and CDC/NOAA for its outstanding on-line data services and plotting utilities. This work was 25 supported by the National Science Council (NSC), Taiwan, under grants 94-2111-M-008-004 and 93-2111-M-007. We would like thank W. Ebisuzaki, M. T. Stoelinga, B. E. Doty, and M. Haley for data management and data visualization tools. The author is very grateful to J. A. Pyle and D. E. Shallcross for their continuous support. These simulations were performed on the DOBSON Cluster, developed in the Atmospheric Chemistry Modelling Laboratory at National Central University.

\section{MM5V3 modeling of the 2002 SH stratosphere \\ K. Wang}

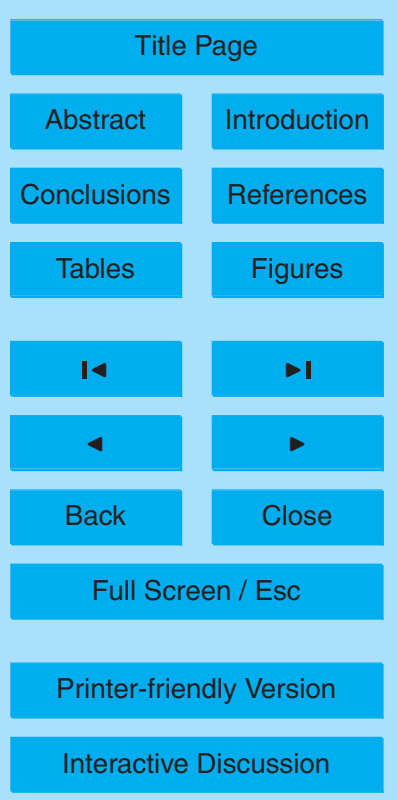




\section{References}

Allen, D. R., Coy, L., Eckermann, S. D., McCormack, J. P., Manney, G. L., Hogan, T. F., and Kim, Y.-J.: NOGAPS-ALPHA simulations of the 2002 Southern Hemisphere stratospheric major warming, Mon. Weather Rev., 134, 498-518, 2006.

5 Allen, M. S.: Evaluation of the mountain wave forecast model's stratospheric turbulence simulations, M.S. thesis, 70 pp., Air University, Ohio, 2003.

Andrews, D. G., Holton, J. R., and Leovy, C. B.: Middle atmosphere dynamics, Academic Press, Inc., 489 pp., 1987.

Anthes, R. A. and Warner T. T.: Development of hydrodynamical models suitable for air pollution and other mesometeorological studies, Mon. Weather Rev., 106, 1045-1078, 1978.

Baldwin, M., Hirooka, T., O'Neil, A., and Yoden, S.: Major stratospheric warming in the Southern Hemisphere in 2002: Dynamical aspects of the ozone hole split, SPARC Newsletter, 20, 2426, 2003.

Charlton, A. J.,O'Neil, A., Lahoz, W. A., and Berrisford, P.: The splitting of the stratospheric polar vortex in the Southern Hemisphere, September 2002: Dynamical evolution, J. Atmos. Sci., 62, 590-602, 2005.

Damiao, M. C., Trigo, R. M., DaCamara, C. C., and Cavalcanti, I. F. A.: A comparison of blocking climatologies for Southern Hemisphere between NCEP-NCAR reanalysis and Hadley Centre model, in Proceedings of 8 ICSHMO, 547-552, Foz do Iguacu, Brazil, April 24-28, 2006.

Dudhia, J. and Bresch, J. F.: A global version of the PSU-NCAR mesoscale model, Mon. Weather Rev., 130, 2989-3007, 2003.

Esler, J. G., Polvani, L. M., and Scott, R. K.: The Antarctic stratospheric suddent warming of 2002: A self-tuned resonance?, Geophys. Res. Lett., 33, L12804, doi:10.1029/2006GL026034, 2006.

Grell, G. A., Dudhia, J., and Stauffer, D. R.: A description of the fifth-generation Penn State/NCAR Mesoscale Model (MM5), NCAR/TN-398 + STR, NCAR Technical Note, 121 pp., 1994.

Kalnay, E., Kanamitsu, M., Kistler, R., et al.: The NCEP/NCAR 40-year reanalysis project, Bull. Am. Meteorol. Soc., 77, 437-471, 1996.

30 Kalnay, E. and Cai, M.: Impact of urbanization and land-use change on climate, Nature, 423, 528-531, 2003.

Kistler, R., Kalnay, E., Collins, W., et al.: The NCEP/NCAR 50-year reanalysis: Monthly means

MM5V3 modeling of the 2002 SH stratosphere

K. Wang

Title Page

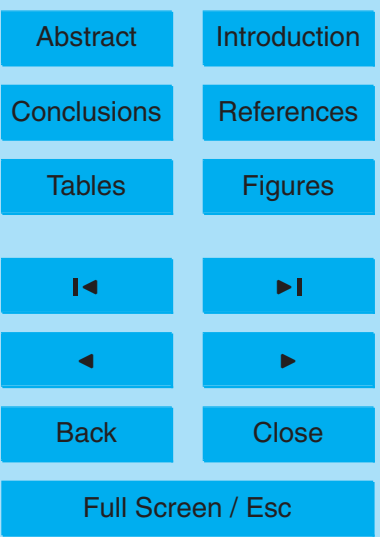

Printer-friendly Version

Interactive Discussion 
CD-ROM and documentations, Bull. Am. Meteorol. Soc., 82, 247-267, 2000.

Kushner, P. J. and Polvani, L. M.: A very large spontaneous stratospheric sudden warming in a simple AGCM: A prototype for the Southern Hemisphere warming of 2002?, J. Atmos. Sci., 62, 890-897, 2005.

5 Liu, H.-L. and Robel R. G.: Dynamical coupling of the stratosphere and mesosphere in the 2002 Southern Hemisphere major stratospheirc warming, Geophys. Res. Lett., 32, L13804, doi:10.1029/2005GL022939, 2005.

Manney, G. L., Sabutis, J. L., Allen, D. R., et al.: Simulations of dynamics and transport during the September 2002 Antarctic major warming, J. Atmos. Sci., 62, 690-707, 2005.

10 Matsuno, T.: A dynamical model of the stratospheric sudden warming, J. Atmos. Sci., 28, 1479-1494, 1971.

Newman, P. A. and Nash, E. R.: The unusual Southern Hemisphere winter of 2002, J. Atmos. Sci., 62, 614-628, 2005.

Nielsen, J. E., Rood, R. B., Douglass, A. R., Cerniglia, M. C., Allen, D. J., and Rosenfield, J.

15 E.: Tracer evolution in winds generated by a global spectral mechanistic model, J. Geophys. Res., 99, D3, 5399-5420, 1994.

Nishii, K. and Nakamura, H.: Tropospheric influence on the dimished Antarctic ozone hole in September 2002, Geophys. Res. Lett., 31, L16103, doi:10.1029/2004GL019532, 2004.

Scaife, A. A., Jackson, D. R., Swinbank, R., Butchart, N., Thornton, H. E., Keil, M., and Henderson, L.: Stratospheric vacillations and the major warming over Antarctic 2002, J. Atmos. Sci., 62, 629-639, 2005.

Shepherd, T., Plumb, R. A., and Wofsy, S. C.: Preface, J. Atmos. Sci., 62, 565-566, 2005.

Simmons, A., Hortal, M., Kelly, G., McNally, A., Untch, A., and Uppala, S.: ECMWF analyses and forecasts of stratospheric winter polar vortex breakup: September 2002 in the Southern Hemisphere and related events, J. Atmos. Sci., 62, 668-689, 2005.

Taguchi, M. and Yoden, S.: Internal interannual variability of the troposphere-stratosphere coupled system in a simple global circulation model. Part I: Parameter seep experiment, J. Atmos. Sci., 59, 3021-3036, 2002.

Varotsos, C.: Why did a "No-oznehole" episode occur in Antarctica?, EOS, 84, 183, 2003.

30 Wang, K.-Y., Shallcross, D. E., Hall, S. M., Lo, Y.-H., Chou, C., and Chen, D.: DOBSON: A Pentium-Based SMP Linux PC Beowulf for distributed-memory high resolution environment modelling, Environmental Modelling and Software, 20, 1299-1306, 2005.

WMO (2002): Antarctic ozone hole splits in two, Press Release 681, 1 October 2002.
MM5V3 modeling of the 2002 SH stratosphere

K. Wang

Title Page

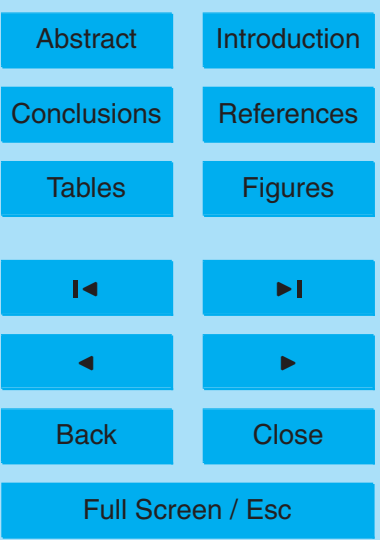

Printer-friendly Version

Interactive Discussion 


\section{ACPD}

8, 7953-7976, 2008

Table 1. Experiment names, nudging domains, and integration domains for this work.

\begin{tabular}{lll}
\hline Experiemnt Names & $\begin{array}{l}\text { Nudging Domains } \\
\text { (Year, Vertical Extent) }\end{array}$ & $\begin{array}{l}\text { Integration Domains } \\
\text { (Year, Vertical Extent) }\end{array}$ \\
\hline Control & none & 2002, All \\
1 & 2002, surface $-325 \mathrm{hPa}$ & 2002, stratosphere \\
2 & 2002, surface $-225 \mathrm{hPa}$ & 2002, stratosphere \\
3 & 2002, surface $-125 \mathrm{hPa}$ & 2002, stratosphere \\
4 & 2002, surface $-70 \mathrm{hPa}$ & 2002, stratosphere \\
5 & 2002, surface $-50 \mathrm{hPa}$ & 2002, stratosphere \\
6 & 2002, surface $-30 \mathrm{hPa}$ & 2002, stratosphere \\
7 & 2002, all model layers & 2002, stratosphere \\
& & \\
8 & 2002, surface $-50 \mathrm{hPa}$ & 1948, stratosphere \\
9 & 2002, surface $-50 \mathrm{hPa}$ & 1998, stratosphere \\
& & \\
10 & 1948, surface $-50 \mathrm{hPa}$ & 2002, stratosphere \\
11 & 1998, surface $-50 \mathrm{hPa}$ & 2002, stratosphere \\
\hline
\end{tabular}

MM5V3 modeling of

the 2002 SH

stratosphere

K. Wang

Title Page

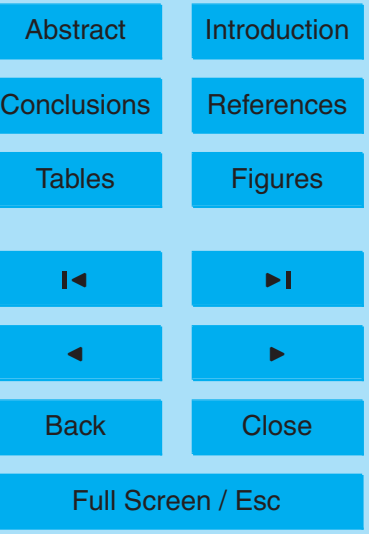

Printer-friendly Version

Interactive Discussion 
ACPD

8, 7953-7976, 2008

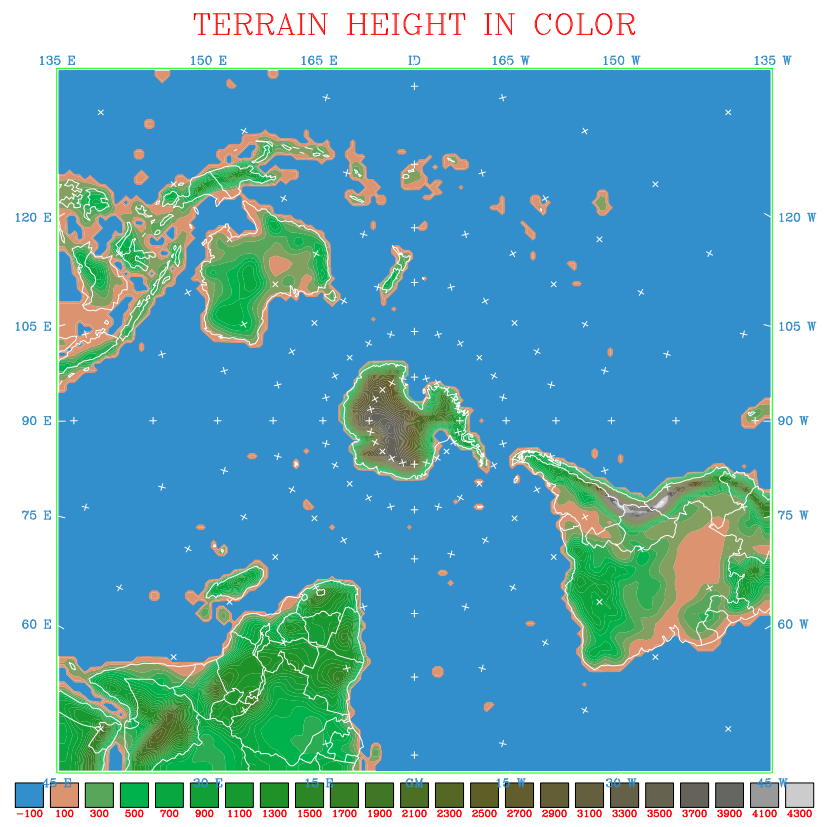

MM5V3 modeling of the 2002 SH stratosphere

K. Wang

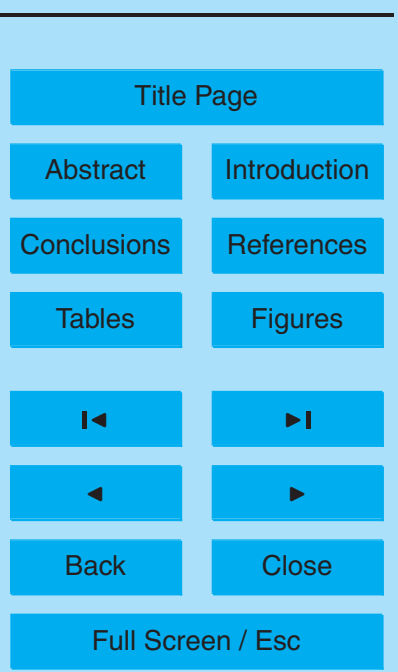

Printer-friendly Version

Interactive Discussion 


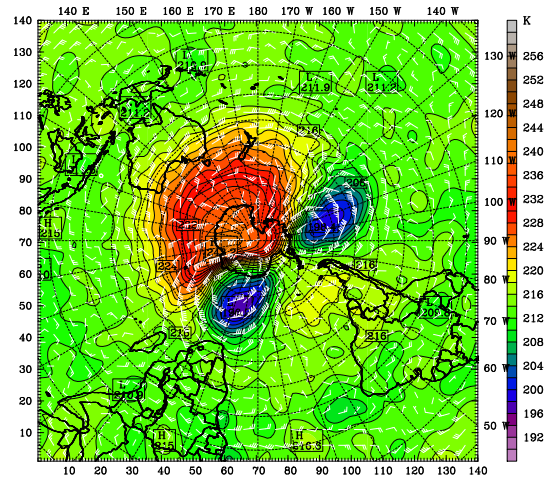

(a)

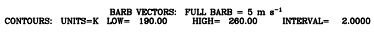

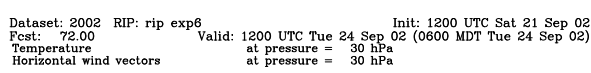

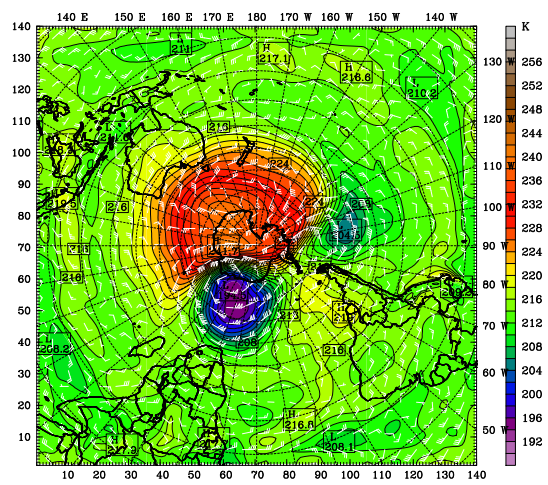

8, 7953-7976, 2008

MM5V3 modeling of the 2002 SH stratosphere

K. Wang

Title Page

Abstract

Conclusions

Tables

14

4

Back

Full Screen / Esc

Printer-friendly Version

Interactive Discussion

Fig. 2. Temperature and winds on the $30 \mathrm{hPa}$ surface at 12:00 UTC on 24 September 2002 from (a) an analysis and (b) a 72-h forecast simulation. 


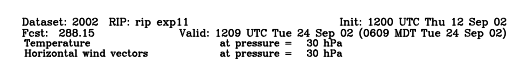

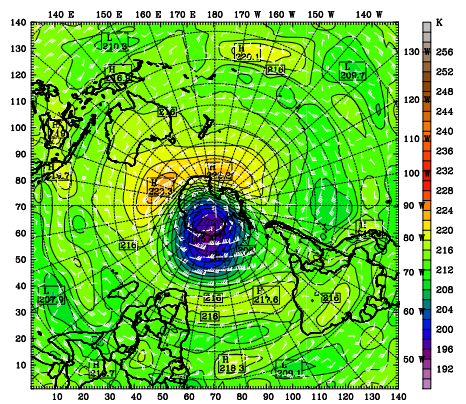

(a)

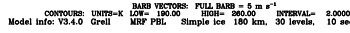

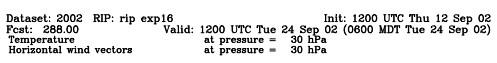

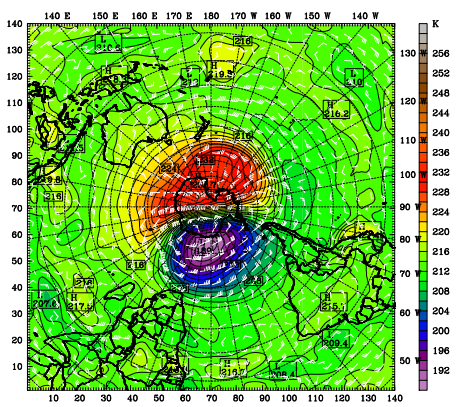

(b)

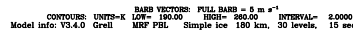

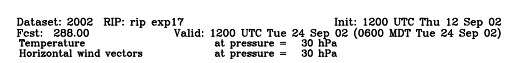

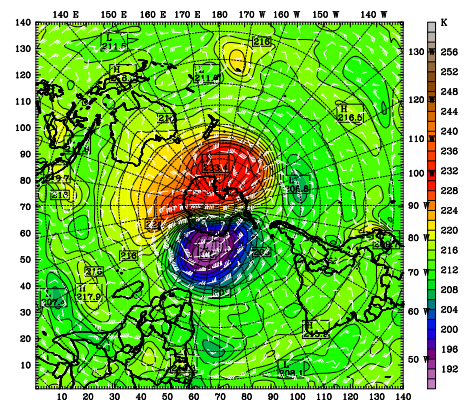

(c)

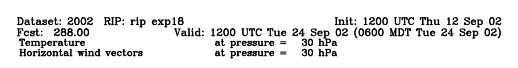

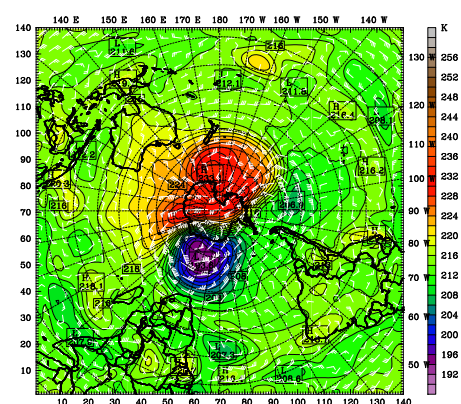

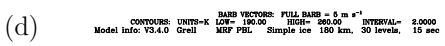

\section{ACPD}

8, 7953-7976, 2008

\section{MM5V3 modeling of} the 2002 SH stratosphere

K. Wang

Title Page

Abstract Introduction

Conclusions References

Tables

Figures

14

4

Back

Close

Fig. 3. Temperatures and winds on the $30 \mathrm{hPa}$ surface from 288-h forecast simulations: (a) without nudging of analysis data; with nudging of analysis data below (b) $325 \mathrm{hPa}$, (c) $225 \mathrm{hPa}$, and (d) $125 \mathrm{hPa}$ surface, respectively. The forecast is verified at 12:00 UTC on 24 September 2002.

\section{Full Screen / Esc}

Printer-friendly Version

Interactive Discussion 


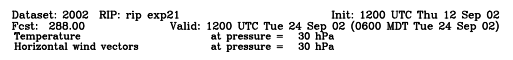

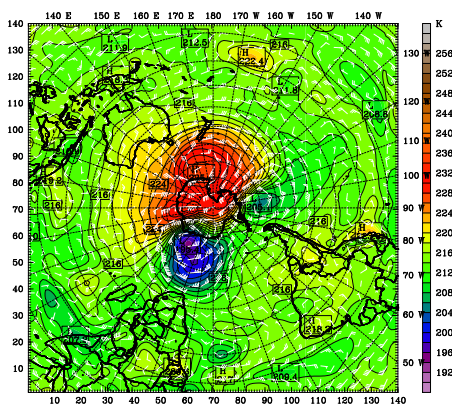

(a)

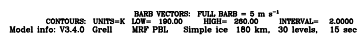

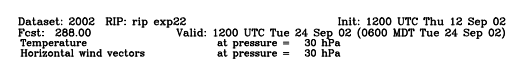

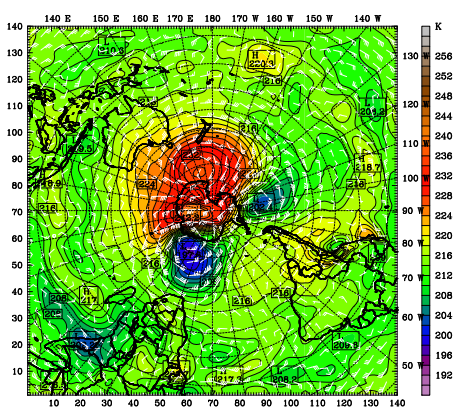

(b)

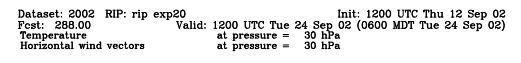

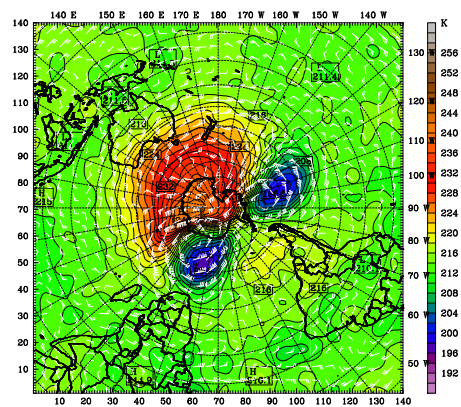

(c)
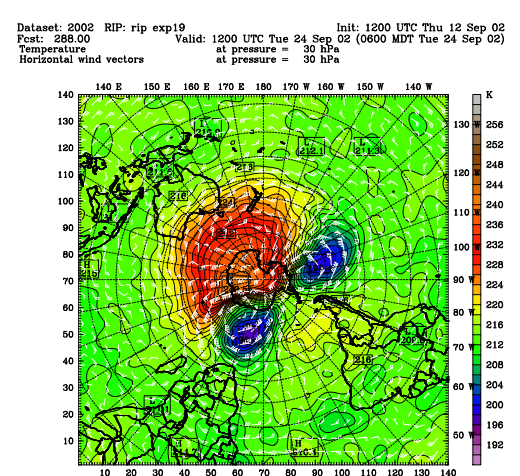

(d)
ACPD

8, 7953-7976, 2008

\section{MM5V3 modeling of} the 2002 SH stratosphere

K. Wang

Title Page

Abstract Introduction

Conclusions

References

Tables

Figures

14

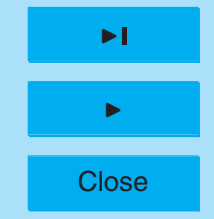

Back

Close

Fig. 4. The same as in Fig. 3 but for nudging of analysis data below (a) $70 \mathrm{hPa}$, (b) $50 \mathrm{hPa}$, (c) $30 \mathrm{hPa}$, and (d) all model layers.

Printer-friendly Version

Interactive Discussion 


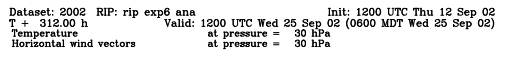

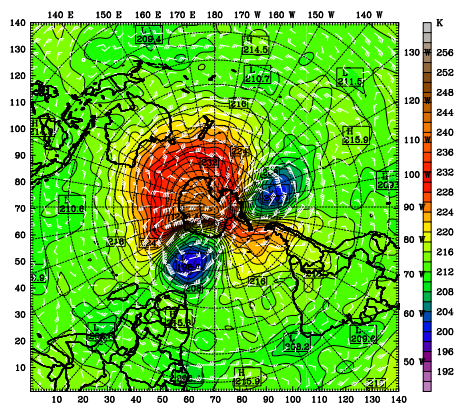

(a)

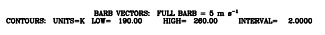

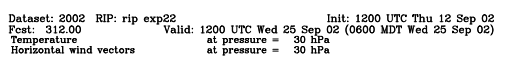

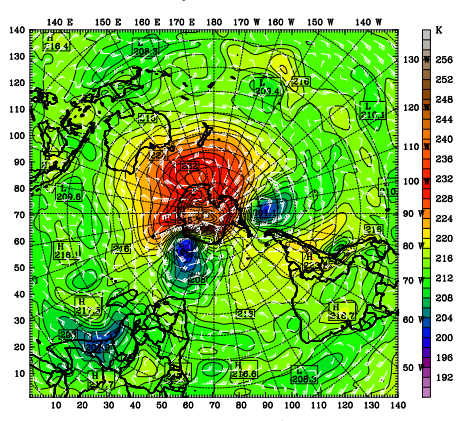

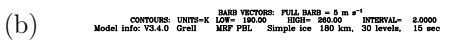

(c)

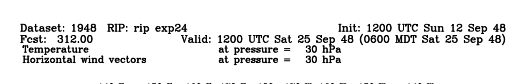

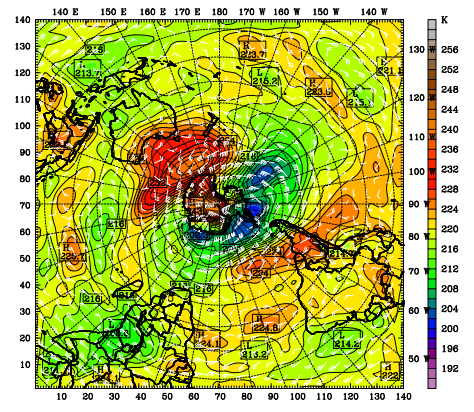

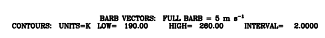

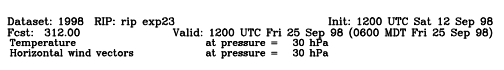

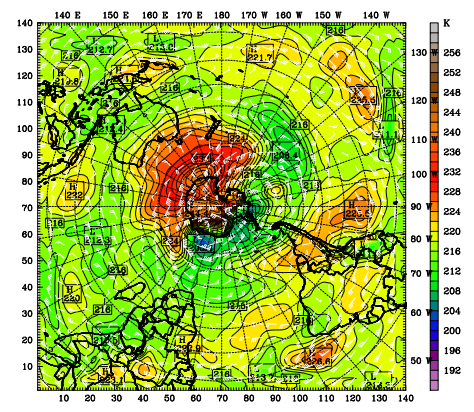

(d)

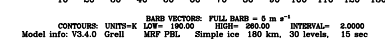

\section{ACPD}

8, 7953-7976, 2008

\section{MM5V3 modeling of} the $2002 \mathrm{SH}$ stratosphere

K. Wang

Title Page

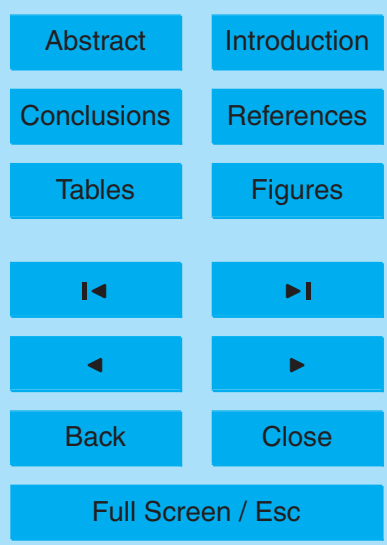

Printer-friendly Version

Interactive Discussion 


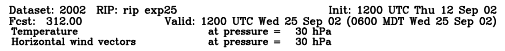

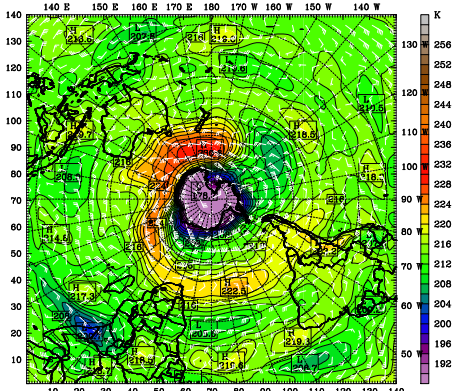

(a)

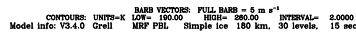

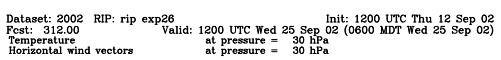

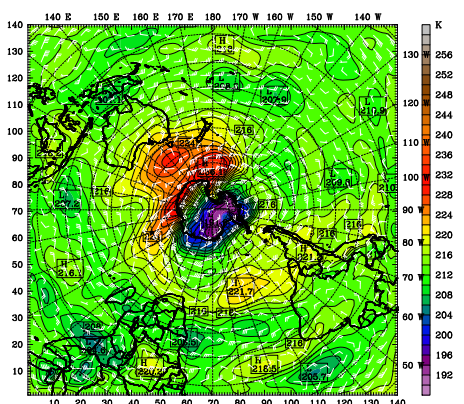

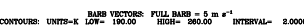

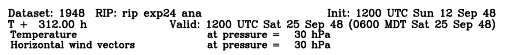

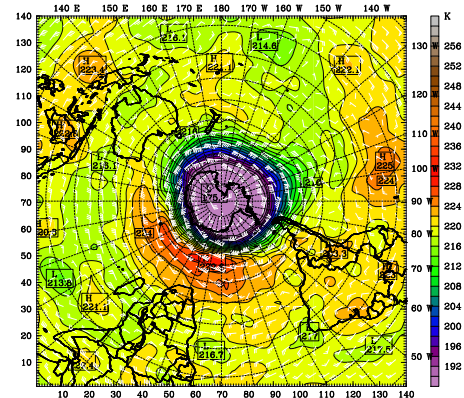

(c)

8, 7953-7976, 2008

MM5V3 modeling of the 2002 SH stratosphere

K. Wang

Title Page

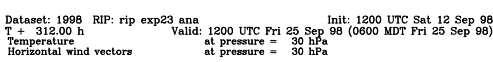

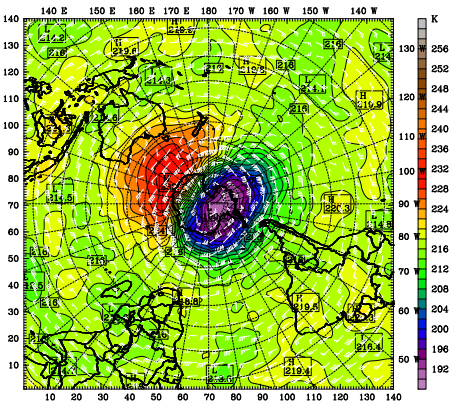

(b)

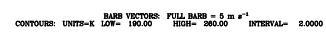

Fig. 6. Test of the 2002 stratosphere, where it was integrated for two 312-h simulations with the troposphere constrained to the (a) 1948 and (b) 1998 conditions, respectively. Temperatures and winds on the $30 \mathrm{hPa}$ surface are validated at 12:00 UTC on 25 September 2006. Analysis for 25 September of (c) 1948 and (d) 1998 are shown for reference.

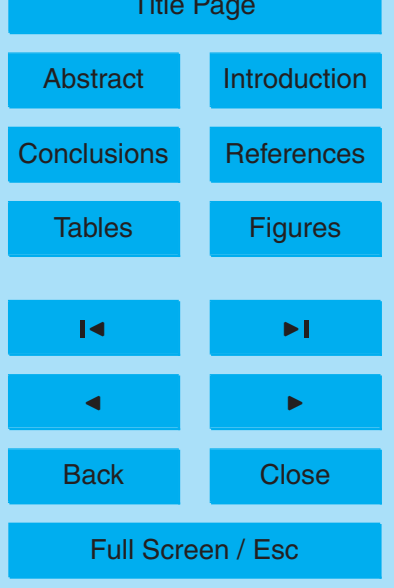

Printer-friendly Version

Interactive Discussion 